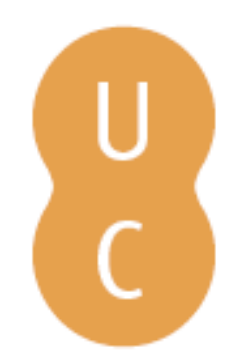

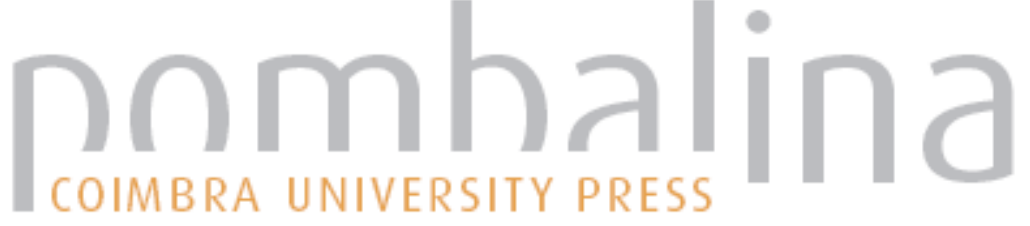

\section{Pensar a Europa: uma perspectiva cultural e política}

\author{
Autor(es): $\quad$ Baltazar, Isabel
}

Publicado por: Imprensa da Universidade de Coimbra

URL

persistente: URI:http://hdl.handle.net/10316.2/47293

DOI: $\quad$ DOl:https://doi.org/10.14195/978-989-26-1849-4_2

Accessed : $\quad$ 26-Apr-2023 15:06:37

A navegação consulta e descarregamento dos títulos inseridos nas Bibliotecas Digitais UC Digitalis, UC Pombalina e UC Impactum, pressupõem a aceitação plena e sem reservas dos Termos e Condições de Uso destas Bibliotecas Digitais, disponíveis em https://digitalis.uc.pt/pt-pt/termos.

Conforme exposto nos referidos Termos e Condições de Uso, o descarregamento de títulos de acesso restrito requer uma licença válida de autorização devendo o utilizador aceder ao(s) documento(s) a partir de um endereço de IP da instituição detentora da supramencionada licença.

Ao utilizador é apenas permitido o descarregamento para uso pessoal, pelo que o emprego do(s) título(s) descarregado(s) para outro fim, designadamente comercial, carece de autorização do respetivo autor ou editor da obra.

Na medida em que todas as obras da UC Digitalis se encontram protegidas pelo Código do Direito de Autor e Direitos Conexos e demais legislação aplicável, toda a cópia, parcial ou total, deste documento, nos casos em que é legalmente admitida, deverá conter ou fazer-se acompanhar por este aviso.

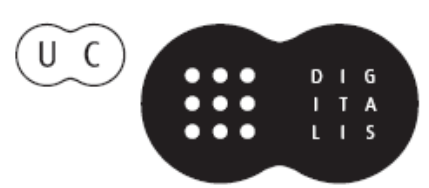


Euro-Atlântico:

Espaço de Diálogos

Isabel Maria Freitas Valente

Iranilson Buriti de Oliveira

(Coord)

\section{VISÕES \\ INTERDISCIPLINARES \\ DA EUROPA \\ E DO MUNDO:}

uma experiência de convergência

disciplinar em homenagem a

Maria Manuela Tavares Ribeiro

Alexandra Aragão

Isabel Maria Freitas Valente

Dulce Lopes

(org.)

Editora da Universidade Federal de Campina Grande

Imprensa da Universidade de Coimbra

2019 


\title{
Pensar a Europa. UMA PERSPECTIVA Cultural E POLÍtica
}

\author{
Isabel Baltazar, $\mathrm{PhD}$ \\ IHC-UNL / CEIS20 \\ E-mail: ibaltazar@fcsh.unl.pt \\ "Europa, sonho futuro! Europa, manhã por vir, \\ fronteiras sem cães de guarda, \\ nações com seu riso franco abertas de par em par! (...) \\ Europa, ó mundo a criar! (...) \\ Europa, tu virás só quando entre as nações \\ o ódio não tiver a última palavra \\ ao ódio não guiar a mão avara, \\ à mão não der alento o cavo som de enterro \\ dos cofres digerindo o sangue do rebanho \\ - e do rebanho morto, enfim à luz do dia, \\ o homem que sonhaste, Europa \\ Adolfo Casais Monteiro, Europa (1945)
}

\section{Resumo}

Estamos num tempo em que, hoje mais do que nunca, é necessário Pensar a Europa. E esta atitude de reflexão não é jurídico-económica, embora a economia e o direito sejam áreas fundacionais, mas trata-se de uma reflexão ao nível da História e Teoria das Ideias, na área das ideias políticas. É fundamental no tempo presente, regressar às origens, aos fundamentos greco-romanos e ao cristianismo como alicerces desta Europa, lembrando que temos uma herança comum que servirá de bússola para encontrar um futuro sólido para a União Europeia

Palavras-chave: Europa; Integração europeia; Cultura. 


\begin{abstract}
We live in a time when, more than ever, it is necessary to think about Europe. And this attitude of reflection is not merely legal or economic, although economics and law are foundational areas, but it is a reflection at the level of History and Theory of Ideas, in the area of political ideas. It is essential at the present times to return to the origins, to the Greco-Roman foundations and to Christianity as the foundations of this Europe, remembering that we have a common heritage that will serve as a magnetic compass to find a solid future for the European Union.
\end{abstract}

Keywords: Europe; Integration; Culture.

\title{
Uma Europa da História e da Cultura
}

É preciso Pensar a Europa a partir destes alicerces da História e da Cultura Europeia, que, embora esta última pareça um mosaico de peças diferentes, na essencialidade nos distingue das outras culturas do mundo. A Europa da Cultura é, por isso, esta "unidade da diversidade", lema da própria União Europeia que também precisa de ser pensado e interiorizado para perceber que a multiculturalidade é uma riqueza da Europa, mas que as diferentes culturas se harmonizam num todo face aos outros continentes.

Pensar a Europa supõe ter uma Ideia de Europa, como mostra magistralmente Manuela Tavares Ribeiro, na obra A Ideia de Europa. Uma perspectiva histórica. ${ }^{1}$ Logo na introdução, leia-se o seu excelente retrato da situação desta Europa que precisa de ser pensada:

"Hoje, mulheres e homens, Europeus e não Europeus interrogam-se sobre o Futuro de uma Europa em plena mutação. Interrogam-se sobre as guerras, sobre a importância das fronteiras terrestres e marítimas, sobre o equilíbrio ecológico, sobre as migrações, sobre as questões

${ }^{1}$ Maria Manuela Tavares Ribeiro, A Ideia de Europa. Uma perspectiva histórica, Coimbra, Quarteto Editora, 2003. 
económicas, sobre os direitos do Homem, sobre os problemas sociais, sobre os meios culturais, sobre a mundialização da informação, sobre as instituições, sobre as sensibilidades políticas, sobre as identidades nacionais, sobre a ideia, a identidade e consciência europeia, sobre a construção da Europa, sobre a(s) Europa (s), sobre a Europa e o Mundo.

O Presente da Europa é feito de dúvidas, de interrogações, de certezas mas também de incertezas. Assim sendo, a busca de compreensão do Presente conduz-nos a caminhos diversos, a questões múltiplas, a questionar o Passado numa tentativa de prefiguração do Futuro". ${ }^{2}$

Estas palavras proferidas quase no início deste milénio parecem uma lição para Pensar a Europa na actualidade, a partir do contributo da História. Lição que precisa de ser reaprendida e, sobretudo, de ser o norte para o futuro da construção europeia. Na verdade, a construção europeia, embora, um projecto de sucesso com quase setenta anos de Paz, objectivo primeiro para o início deste caminho de integração, tem vivido de constantes aprofundamentos registados nos Tratados Europeus e nas políticas económicas e sociais cada vez mais aprofundadas, resultantes de um crescimento rápido que não teve o tempo de maturidade para se pensar a si própria. É por isso que vive tempos de crise, como salienta Vitorino Magalhães Godinho, na obra A Europa como Projecto. ${ }^{3}$ Nela são detectados os erros de institucionalização e de refundação que está na hora de pensar para reconstruir o futuro do projecto europeu, dando atenção a fundamentos sólidos que unam os países num Espírito Europeu comum, para além do EuroCorpo construído de necessidades imediatas e conjunturais. A Europa, dizemos muitas vezes, não é um projecto acabado e está na altura de Pensar a Europa numa perspectiva histórico-cultural e política, de forma aprofundada, para dar resposta aos problemas actuais provocados por populismos, nacionalismos emergentes que questionam partilhas de soberania, crise de refugiados, xenofobias e todos os problemas sociais emergentes que afastam os

\footnotetext{
2 Idem, Ibidem, p. 9.

3 Vitorino Magalhães Godinho, A Europa como Projecto, Lisboa, Edições Colibri, 2007.
} 
Europeus de um envolvimento no projecto da União Europeia, ou, num cenário limite, os levam de uma apatia a uma antipatia ou mesmo recusa do projecto, cuja consequência máxima levou ao Brexit.

Como recorda Vitorino Magalhães Godinho:

"A Europa não é uma construção acabada, e deixou mesmo de ser um projecto. Está a sofrer de uma crise que não consegue gizar-lhe os alicerces nem definir-lhe a traça. Perdeu-se a confiança em que se resolva os problemas instantes que se nos põem, não se acredita nos dirigentes, falta um ideal e um ideário que impulsionem e orientem a acção; quanto a realizações estamos perante uma manta de retalhos e resignamo-nos a discursos de vã retórica, a iniciativas descosidas, a medidas que só servem a interesses de alguns. Fala-se muito de refundar a Europa, em levá-la a um novo arranque - mas só se propõem estafadas soluções que evitam atacar o mal, e teima-se em tratar de tudo em circuito fechado, sem participação dos cidadãos, escamoteando a vontade geral". ${ }^{4}$

Segundo este historiador, cometeram-se vários erros quanto à forma de institucionalizar a Europa e distorceu-se o sentido do projecto europeu. Faltou uma concepção clara das traves mestras da construção europeia e procedeu-se a um alargamento sem que nada estivesse preparado para um empreendimento de tal dimensão e que uma União conseguisse funcionar bem com tantos Estados-Membros. Outro problema que temos na actualidade é que os actores principais da Europa parecem não conhecer a História nem se servir das lições do passado para construir o presente. É necessário Pensar a Europa numa perspectiva Histórica e Cultural porque qualquer fundação precisa de ter ideias muito bem definidas sobre a História, muito particularmente sobre a História da Europa. De facto, a Europa actual é fruto de toda a sua História e o projecto europeu já foi experimentado de várias formas e em várias épocas, desde o tempo de um Império Romano,

${ }^{4}$ Idem, ibidem, p.7. 
ao tempo de uma Europa Unida pela força do Nazismo. É preciso aprender a História dos Fascismos, Ditaduras e Totalitarismos, para não repetir erros passados. É preciso juntar as Elites Intelectuais de grandes pensadores da Europa com políticos carismáticos que tenham uma visão da Europa.

O próprio Jacques Delors reconheceu que a Europa perdera o sentido da História e se tornou um Objecto Político Não Identificado (OPNI), perdendo-se também o sentido da Europa. Por outro lado, A Europa no Mundo não passa de um instrumento do imperialismo norte-americano e esta Americanização da Europa sente-se na própria cultura e falta de Identidade Europeia. Esta falta de voz e de rosto europeu, levou Henri Kissinger a interrogar-se sobre qual o número de telefone da Europa, em sentido metafórico, para significar a ausência de protagonismo europeu. No entanto, esta Europa, a velha Europa, é essencial como referência cultural ao Mundo e é exemplo de Valores essenciais a toda a humanidade. Que caminho seguir, nesta encruzilhada europeia? É preciso abrir outro caminho e Jacques Delors apontou a necessidade de os chefes de Estado e de governo se interrogarem em conjunto sobre as finalidades da Europa e o que desejavam construir em conjunto e que fariam gradualmente num compromisso duradouro mas dinâmico. ${ }^{5}$

No entanto, a Europa dos Cidadãos foi esquecida e o projecto europeu é para eles e precisa de os ouvir, para além dos negativos referendos e manifestações ou problemas culturais de falta de unidade na diversidade cultural, pela tentativa de imperialismos culturais, não esquecendo a questão dos populismos e dos refugiados. É preciso a "Nova Narrativa para a Europa" já anunciada em 2014, mas ainda sem realização. Também urge voltar a dar uma "Alma à Europa" anunciada por Durão Barroso, em Berlin de 2005. Por fim, lembrar os Encontros de Paris, de 2008, que reuniram 800 intelectuais de toda a Europa, com a representação portuguesa de Fernando Gil, mostrando dar valor aos intelectuais e a essa Europa da Cultura que necessita de ser recuperada. Pensar a Europa com a formação de grupos de reflexão e de estudo,

\footnotetext{
5 Jacques Delors, Jornal L'Express, 22 de Março de 2007.
} 
compostos por intelectuais, escritores, artistas, geógrafos, historiadores, pensadores políticos, filósofos, é a solução proposta por muitos, entre os quais, Vitorino Magalhães Godinho no seu Projecto Europeu. ${ }^{6}$

Hans- Georg Gadamer, na sua obra Herança e Futuro da Europa ${ }^{7}$, enuncia profundamente a questão da necessidade de Pensar a Europa a partir da sua História e Cultura, salientando a diversidade da cultura europeia, mas, também, essa unidade face aos outros continentes. Escreve ele nos seus 85 anos, narrando como viveu uma História tumultuosa e de que nenhuma teoria é independente da situação política social e da prática política do seu tempo. Sobrevivente de duas guerras Mundiais, interroga-se sobre o que aprendeu com isso porque ninguém vive numa torre de Marfim. Também toda a História anterior às catástrofes faz compreender os acontecimentos e a necessidade de um equilíbrio global:

"Estou muito longe de idealizar a história que precedeu as catástrofes das duas guerras mundiais. Em todo o caso, por sua causa produziuse uma mudança tão colossal que não diz respeito apenas à posição da Europa no mundo e, com isso, a todas as expectativas de uma juventude que tanto então como agora procura o seu difícil caminho num panorama mundial incerto. A época das guerras mundiais deu dimensões globais a todas as coisas. Em política já não se trata do equilíbrio de forças na Europa, esse princípio fundamental de todas as actividades de política externa que todos compreendiam. Desde essa altura, trata-se de um equilíbrio global, da questão da coexistência de enormes concentrações de poderes. Até as palavras economia nacional, que ainda continuamos a usar soam completamente obsoletas. O que são as nações, o que é a economia nacional, na era das multinacionais, na era da economia mundial, numa era que recebeu a sua autêntica fisionomia através da Revolução Industrial? Tudo isto é, decerto, consequência dos enormes avanços técnicos, estimulados pelo furor

\footnotetext{
${ }^{6}$ Vitorino Magalhães Godinho, op. cit., p.11.

${ }^{7}$ Hans-Georg Gadamer, Herança e Futuro da Europa, Lisboa, Edições 70, 2009.
} 
destruidor de duas guerras mundiais".

A Europa, e não só a Europa mas o mundo, chegou a uma nova situação fruto da sua História que é urgente pensar. Já não temos a nossa "casa comum europeia" afastada do mundo globalizado. A Europa continua a ser um segmento rico e diverso na sua cultura, um legado único para o mundo, mas arrastada para o mundo e sofrendo a sua influência. Estamos implicados nos acontecimentos mundiais, somos ameaçados por eles, e não nos limitamos à nossa pequena pátria europeia. Sofremos pela lógica interna dos acontecimentos, que nos conduzem a fenómenos extremos, como a criação de um arsenal de armas, "cuja utilização já não promete a vitória de ninguém, mas que significaria o suicídio colectivo da civilização humana. E existe, além disso, algo talvez mais grave - porque, que eu saiba, ninguém vê de que modo poderíamos dominar esta crise -, a crise ecológica, o esgotamento, a desertificação e a devastação dos recursos naturais". ${ }^{8}$

A velha Europa globalizada conseguirá, talvez, sobreviver se aprender a usar o seu poder e capacidade de acção. Por isso, a União Europeia é fundamental para haver esta força da unidade de história, da cultura e dos valores europeus.

\section{Um pragmatismo Político}

Perante este cenário, é urgente encontrar razões mais profundas para a União da Europa e conseguir também Unir os Europeus numa Europa Unida pelas pessoas e não pelas instituições, evocando os Pais da Europa, muito particularmente Jean Monnet, e a sua advertência da necessidade de unir homens e não instituições, ainda muito longe de ser seguida. A Europa é este projecto inacabado e chegou o momento em que é preciso Pensar para Agir. Nesta perspectiva, é fundamental voltar a ler as Memórias dos Fundadores da Europa, muito particularmente,

8 Idem, Ibidem, p.10. 
as Memórias de Jean Monnet ${ }^{9}$, para reorientar o caminho. Jean Monnet foi essencialmente um homem de acção e não um político, no sentido usual do termo, a "power politics". Pretendia fazer uma verdadeira revolução política, na maior discrição e fundamentada na acção. Tỉnha consciência que o Ideal Europeu tinha sido amplamente divulgado na Europa da primeira metade do seculo XX e, afinal, com tão poucos resultados:

"Quando consideramos este período, que correspondia a metade do século, chama-nos a atenção a extraordinária efervescência intelectual que havia em torno do ideal europeu. Se relermos os manifestos dos partidos e dos movimentos militantes, as declarações dos dirigentes políticos e os artigos na imprensa - o Economist e o Times de Londres publicavam editoriais dignos do Federalista de Jay, Hamilton e Madinson -, temos o sentimento de que uma corrente de pensamento tão rica coma essa só podia levar à realização da mais ampla unidade europeia. E é verdade que o vocabulário e a dialéctica comunitárias de hoje em dia já estavam fixadas na época, mas isso não tinha nada a ver com a acção. Em 1946, em Zurique, Churchill apelava no sentido da criação urgente dos Estados Unidos da Europa mas tinha em mente o Conselho da Europa. Em 1929, em Genebra, Briand preconizara uma ligação federal entre os povos da Europa- mas tinha especificado que os direitos soberanos dos Estados não seriam com isso afectados. Não obstante, a opinião estava convencida de que as fórmulas mágicas tinham sido pronunciadas e não compreendia que a realidade resistisse de forma tão obstinada. Em 1949, continuávamos na gramática, e erame difícil interessar-me por isso".

Lendo Jean Monnet, temos consciência de que as elites intelectuais sempre estiveram na origem da construção europeia e de que as suas Ideias de Europa inspiraram os políticos no processo de construção europeia, desde o seu alvor. No entanto, foi sempre difícil passar das

9 Jean Monnet, Memórias, Lisboa, Editora Ulisseia, 2004. 
ideias à prática, porque a realidade exigia um pragmatismo difícil de coadunar com elevados ideais, mas impossíveis de realizar no momento. Jean Monnet percebia que era necessária uma Europa reconciliada consigo mesmo e conhecia bem os anteriores esforços de concretização de uma unidade europeia, sobretudo a partir de Haia, em 1948, e ainda sem êxito. Tudo se passava ao nível da mera cooperação, e mesmo no domínio económico, as tentativas de integração continuavam por realizar. Era essa a realidade da Organização Europeia de Cooperação Económica (1948) e do Conselho da Europa, ao nível politico, iniciada a 5 de Maio de 1949.

Jean Monnet optou por redigir, em Abril de 1950, um documento onde preparou o essencial da Declaração de Maio, apresentando a proposta e os motivos que a fundamentavam, sem as habituais consultas ministeriais, para que tudo fosse feito na maior discrição, não esbarrando logo de início com as habituais objecções e tivesse um sucesso e impacto maior. Um plano revolucionário tinha de usar meios também surpreendentes. Era claro para Jean Monnet que os governos não pretendiam quaisquer cedências de soberania e que era ilusório pretender criar uma integração europeia completa. Assim, a única solução seria a de criar um edifício institucional de forma lenta, mas concertada, apenas em domínios concretos, que não pusessem em causa grandes transferências de soberania. Era necessária uma grande perspicácia e uma grande audácia, mascarada por uma hábil diplomacia. A diplomacia clássica era substituída por uma nova, ainda mais discreta e cuidadosa, que afastasse juízos apressados e reacções negativas. Primeiro França, depois a Alemanha, protagonizada por Adenauer. Só depois seria tornada pública a declaração feita por Robert Schuman numa conferência de imprensa em Quai d'Orsay:

"Não e uma questão de palavras vãs, mas um acto ousado, um acto construtivo. A França agiu e as consequências da sua acção podem ser imensas. Esperemos que assim seja. Agiu essencialmente pela paz. Para que a paz possa verdadeiramente ter a sua oportunidade, é necessário que primeiro exista uma Europa. Quase exactamente cinco anos após 
a capitulação sem condições da Alemanha, a França cumpre o primeiro acto decisivo da construção europeia e associa a esse acto a Alemanha. Com isto, é de esperar que as condições da Europa se transformem completamente. Essa transformação permitirá outras acções comuns até agora impossíveis. Tudo isto será o nascimento da Europa, uma Europa estreitamente unida e solidamente construída" ${ }^{10}$.

A Europa não seria construída de uma só vez, far-se-ia por meio de "realizações concretas", criando antes de mais uma "solidariedade de facto, eliminando a velha oposição entre a França e a Alemanha, através da realização de uma obra comum, como alertava sempre Jean Monnet. Não se tratava de negociar vantagens, mas de encontrar vantagens individuais na vantagem comum, eliminando da discussão sentimentos particularistas. A solução era mudar o método de negociações políticas e transformar os espíritos dos europeus, no sentido de criar essa Comunidade Europeia que desejava criar. Jean Monnet estava convencido de que a Europa seguiria o seu caminho através das propostas políticas revolucionárias de Robert Schuman, embora fosse difícil propor a igualdade das nações, muito particularmente da Alemanha. Mas esta "comunidade" evitaria aquilo que julgava ser a maior calamidade do mundo, o espírito de discriminação. Era o início de um longo e aglutinador processo de unir os homens europeus, criando instituições que servissem os seus interesses comuns. Para Monnet, os "Estados Unidos da Europa" já tinham começado, e o princípio seria sempre o mesmo, quer entre duas, seis ou vinte e oito nações:

"Criar progressivamente entre os homens da Europa o mais vasto interesse comum gerido por instituições comuns e democráticas nas quais se delega a soberania necessária: eis a dinâmica que não deixou de funcionar desde o início da Comunidade Europeia, quebrando preconceitos, apagando fronteiras, alargando em poucos anos a dimensão de um continente o processo que ao longo dos séculos tinha

\footnotetext{
10 Fac-simile do projecto definitivo da Declaração de 9 de Maio de 1950, Fundação Jean Monnet para a Europa,Lausana.
} 
formado os nossos velhos países" 11 .

Jean Monnet tinha consciência de que as suas ideias eram grandes demais para o seu tempo, mas projectavam um futuro no qual acreditava e que continua por realizar: a construção europeia a partir dos seus cidadãos, uma cidadania activa, emergente desde 1992, com o Tratado de Maastricht, onde a cidadania nacional se conjuga com uma cidadania europeia. É preciso repensar esta Europa a partir do pensamento das grandes figuras fundadoras, para privilegiar as pessoas sobre os estados, e envolver os cidadãos europeus na construção dessa "Comunidade", única solução para evitar mais problemas emergentes de um Não à Europa nos referendos, ou de uma apatia dos que não votam. O desafio de Jean Monnet de "unir os homens a partir de instituições comuns" é o método e a solução para a Europa actual. A perspectiva política desta figura fundadora foi a de ver o início da Europa como uma construção comum de interesses dos povos e não de acordos económicos, estes estando contidos num projecto mais alargado. O começo da Europa tinha esta perspectiva política, mas, também, moral: os europeus tinham perdido, pouco a pouco, a capacidade de viver juntos e de associar as suas forças criadoras. Não serão palavras proféticas para os tempos que vivemos?

Jean Monnet morreu no dia 16 de Março de 1979, aos 90 anos. No centenário do seu nascimento, o presidente francês lembrava as virtudes do Primeiro Cidadão da Europa e a necessidade de seguir o seu exemplo:

"Imagino os futuros empreendedores, os futuros fundadores que, a exemplo de Jean Monnet, olharão em seu redor e verão outra Europa, outra parte da Europa: o mesmo continente, as mesmas fontes, a partir das quais foi construída a nossa sociedade, apesar das divisões e dos desentendimentos superarem uma vontade unitária, a outra Europa que virá, nas próximas décadas, os projectos, os acordos, as evoluções, as

${ }^{11}$ Jean Monnet, Mémoires, p. 615. 
ambições e os outros sonhos que nos permitirão perceber que a Europa são todos os Europeus". 12

Os futuros empreendedores, os futuros europeus, somos nós, as gerações vindouras que muito podem usufruir do exemplo e da obra de Jean Monnet e de todas as outras grandes figuras da construção europeia que nos legaram uma herança que é o futuro da Europa. Esta herança precisa de ser relida e repensada, sob pena de não aprendermos lições que a História nos ensina e que servem de fonte e inspiração para as crises do presente e horizonte futuro. Estes Homens não podem ser esquecidos e Jean Monnet foi um pioneiro desta Comunidade Europeia que precisa de recuperar a sua essência que é a de centrar-se nos Europeus. Foram merecidas as palavras de Henry Kissinger quando the entregou o prémio Grenville Clark na homenagem que precisamos de repetir:

"Há poucos homens ou mulheres de que possa dizer-se que a sua vida deu um novo rumo à época em que viveram. São ainda menos aqueles que souberam elevar-se acima da gestão de negócios quotidianos para conceber um ideal a que se esforçavam por dar corpo. Pode dizer-se, penso, sem risco de erro, que nenhum homem neste mundo marcou e modificou a vida política da nossa época mais que aquele que hoje homenageamos".

Muitos outros vultos contribuíram para a unidade europeia contemporâneos do próprio Jean Monnet: Coudenhove-Kalergi, Aristide Briand, Robert Schuman, Alcide De Gasperi, Paul-Henry Spaak ou Clarles de Gaulle. Como lembra Eric Roussell ${ }^{13}$, a Europa teve muitos pais espirituais. A Europa continuou na sua História a ter grandes Figuras inspiradoras. É preciso dar-lhes atenção e aprender com elas a encontrar soluções para esta Europa que vive numa encruzilhada.

12 François Miterrand, Jean Monnet, Lausanne, Fondation Jean Monnet pour L'Europe, 1989, p. 15.

13 Eric Roussel, Jean Monnet, Paris, Fayard, 1996, p.21. 
Pensar a Europa é acreditar que depois de uma crise, virá o crescimento e de que as crises são oportunidades para o aperfeiçoamento de um projecto que salvaguardou a Paz e os Valores Humanos e que serve de baluarte para o resto do mundo. A Europa tem um longo caminho que sobreviveu a tempestades e renova a esperança no futuro:

"As raízes da Comunidade são agora fortes e estendem-se no solo europeu. Sobreviveram as estações más e podem suportar outras iguais. A superfície, as aparências mudam, e é normal que ao longo e um quarto de seculo as gerações se sucedam com ambições diferentes, que as imagens do passado se apaguem e que o equilíbrio do mundo se renove. Quando se vê a persistência do sentimento europeu nesta paisagem em plena mutação e a estabilidade das instituições comunitárias, não se pode duvidar de que se trata de uma dinâmica poderosa, à medida das épocas da história". ${ }^{14}$

A Europa vive tempos sombrios e muitos falam da sua agonia. Não podemos adivinhar o seu futuro, mas podemos contribuir para Pensar a Europa. Uma Europa que retome os ideais dos seus fundadores que encontraram uma solução para problemas limite como o dos conflitos mundiais. Também haverá novos rumos para construir a Europa actual, resolvendo cada problema a seu tempo e que também incluem preocupações já vividas e ultrapassadas:

"Nunca duvidei de que tal processo nos há-de levar um dia a uns Estados Unidos da Europa, mas não procuro imaginar hoje em dia o respectivo quadro politico, de tal forma são imprecisas as palavras que suscitam discussão - confederação ou federação. Aquilo que estamos a preparar, através da acção da Comunidade, provavelmente não tem precedente. Esta Comunidade assenta, ela própria em instituições que há que reforçar, mesmo sabendo que a verdadeira autoridade política de que um dia as democracias europeias vão dotar-se está por conceber e por realizar. Aqueles que não querem empreender nada por

${ }^{14}$ Jean Monnet, Memoires, op. cit., p.615. 
não terem a certeza de que as coisas evoluirão tal como decretaram antecipadamente estão condenados a imobilidade. Ninguém e capaz de dizer hoje qual será a forma que terá a Europa onde havemos de viver no futuro, já que a mudança que resultará da mudança é imprevisível. Amanhã é outro dia ... Bastam as dificuldades de cada dia”. ${ }^{15}$

Porquê a Europa - Geografia, História e Cultura da Unidade Europeia? Porque é mesmo por esta Europa que temos de começar para construir um projecto europeu com raízes que lhe permitam sobreviver aos conflitos internos da União Europeia e aos desafios mundiais. Como lembra Francisco Lucas Pires, "é mesmo por uma Ideia de Europa que se tem de começar, pois é a partir daí que se pode contribuir para a formação crítica dos cidadãos, nomeadamente os mais jovens"16. Na sequência de Maastrich, a Europa só pode construir-se como acto de vontade dos cidadãos e de inteligência, e não apenas como um produto de necessidade económica. A Europa dos Cidadãos será a de concretizar o enunciado daquele preâmbulo do Tratado e a solução para dar um sentido ao projecto europeu na actualidade.

A Europa atravessou episódios da sua História que lhe permitem criar um futuro novo: em 1989, ruiu o Muro de Berlim, que durante quase meio século a manterá numa espécie de guerra civil latente; Em 1991, caiu na União Soviética o império e a ideologia que mais haviam transgredido e dividido a consciência europeia e a Perestroika anuncia a possibilidade do reconhecimento, continuidade e sua identidade. Em 1993, a emergência do Mercado Único dos Doze, é a consumação do fim das fronteiras políticas e económicas, em que as velhas fronteiras europeias dão lugar a uma comunidade alargada e a uma Nova Europa. A Comunidade Europeia transforma-se em União Europeia, com uma moeda única, uma cidadania europeia, uma política externa e de segurança comuns e uma cooperação judicial e policial organizada, fazendo lembrar o velho sonho Pan-Europeu de Coudenhove-Kalergi.

\footnotetext{
15 Idem, ibidem, p.616.

16 Francisco Lucas Pires, o que é Europa, Lisboa, Difusão Cultural, 1992, p.13.
} 
Foram dados todos os passos para "recriar a Família Europeia", desejada por Winston Churchill no Discurso de Zurique de 1948. Pareciam criadas as condições para um aprofundamento do Projecto Europeu.

No entanto, a Europa vive tempos de crise e de incerteza quanto ao seu futuro, e parece que o "big-bang" dos anos noventa, se transformou no novo milénio numa caixa de Pândora de onde saem todas as preocupações. A esperança de um novo século europeu não se concretizou numa União Europeia mais forte para si mesma e para o mundo.

É preciso um renascimento europeu, a partir da História e da Cultura, reconhecendo uma identidade física, histórica e cultural na União Europeia e caminhando do ideal para o real, do sonho para a realidade, através desta Identidade Europeia feita da História, Cultura e Geografia, que parecendo não existir no seu interior, se revela para o mundo e se visualiza de um outro continente. É a partir desta herança que se poderá (re)construir o futuro da Europa. 